\title{
E.Ю. АЖЕЕВА
}

\section{Исторический метод библиографоведения Э.К. Беспаловой}

Реферат. Научное наследие Э.К. Беспаловой, видного российского библиографоведа, теоретика и историка библиографии, включает более 200 работ. Ею проложена собственная линия теоретического и методологического осмысления библиографической науки и деятельности. «Формирование библиографической мысли в России (до 60-гг. XIX в.)»- последний фундаментальный труд Э.К. Беспаловой, в котором изложена философско-методологическая экспликация библиографии как закономерно складывающегося явления информационной природы. Сформировался уникальный метод анализа, рассматривающий историко-библиографические факты в контексте профессионализации библиографической деятельности. Анализ библиографических явлений, применяемый Э.К. Беспаловой, обобщенно можно обозначить как сочетание современного теоретического знания о библиографии, методологии системно-деятельностного подхода и философии исторического процесса. Историко-теоретический метод изучения библиографической деятельности на разных этапах ее развития позволяет современному исследователю увидеть институциональную значимость библиографических процессов как одного из полноценных слагаемых мировой информационной картины.

Анализируя исходный, первоначальный объект библиографической деятельности - книгу, ученый доказывает, что именно процесс тиражирования, а значит и необходимость создания вторичной структуры книги в виде титульного листа, сделали книгу «книгой». Также Э.К. Беспалова через понятие «Книга» прослеживает взаимодействие и последовательную связь трех систем - «знание», «Книга» («документ») и «библиографический документ». С точки зрения познавательного потенциала истории библиографоведения представляет историко-теоретический интерес библиографическое пособие как результат деятельности и объект распредмечивания в нем концептуальных теоретико-методологических и исторических представлений авторов-составителей, действующих лиц истории библиографии. В качестве главной дифференциации библиографической продукции Беспалова выдвигает деление на таймерные библиографические подсистемы (отражение текущего, ретроспективного, перспективного первичного потока) и хорографические подсистемы, ограничивающие документальные потоки по территориальному и языковому принципу. Исторический метод Э.К. Беспаловой раскрывает широкий пласт теоретических оснований, обогащающих современное библиографоведение.

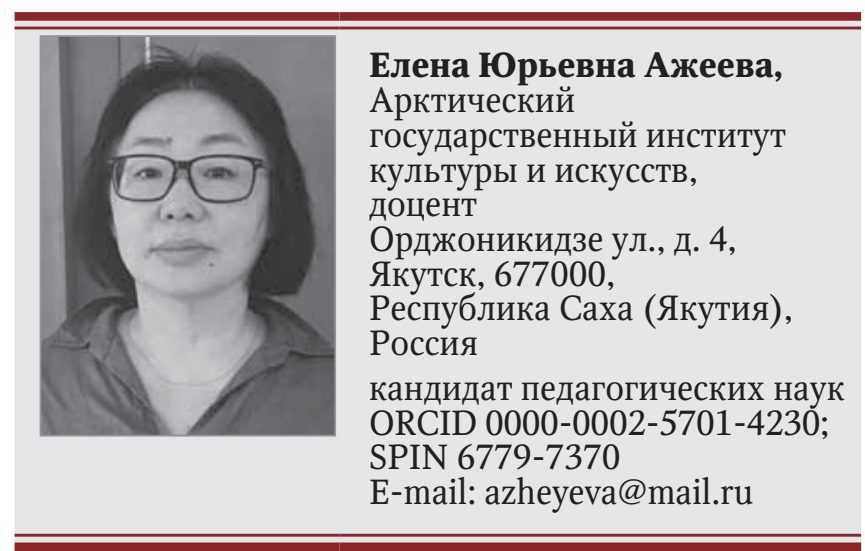


Ключевые слова: Э.К. Беспалова, история библиографии, теория библиографии и библиографоведения, технология и методика библиографирования, методология истории библиографии, историческое библиографоведение, история библиографической мысли, теория исторического процесса, библиографоведение.

Для цитирования: Ажеева Е.Ю. Исторический метод библиографоведения Э.К. Беспаловой // Библиотековедение. 2020. T. 69, № 4. C. 399-407. DOI: 10.25281/0869-608X-2020-69-4-399-407.

$Э$ милия Константиновна Беспалова - уникальное имя в российском библиографоведении. Научное наследие видного российского библиографоведа, теоретика и историка библиографии включает в себя более 200 работ. Она проложила собственную линию теоретического и методологического осмысления библиографической науки, возвысив ее до высот философско-методологического анализа. Прошло более 10 лет, как ее нет с нами, но можно с полной уверенностью сказать о существовании научного метода Беспаловой - особого подхода к анализу библиографических явлений, сформировавшего историко-теоретическое направление в отечественном библиографоведении. Последний труд ученого - «Формирование библиографической мысли в России (до 60-гг. XIX в.)» [1] - квинтэссенция научного творчества Э.К. Беспаловой, плод длительных историко- и теоретико-библиографических размышлений библиографоведа, в котором, собственно, реализован метод ученого.

Метод Э.К. Беспаловой был выработан на основе методологического синтеза многих наук - философии истории, книговедения, библиографоведения, эпистемологии. Она с большим интересом углубилась в историю библиографической мысли, увидев в ней истоки и семена современного концептуального знания о библиографии, а также обнаруживая богатый потенциал теоретического и методологического среза развития библиографоведения. Произошла ситуация, когда системно-деятельностная теория библиографии, разработанная по принципу восхождения от абстрактного к конкретному, дала импульс для анализа любого библиографического объекта по обратному принципу - от конкретного к абстрактному. Досконально зная событийно-фактографическую историю российской библиографии, Эмилия Константиновна подвергла тщательной теоретической экспертизе все возможные метаинформационные процессы, обращенные к двум ключевым элементам системы «доку- мент - потребитель информации» («Д - П») в динамике их зарождения, упрочения, трансформации. Вернее сказать, была применена комплексная методология, включающая «гипотетико-дедуктивный метод... историко-генетический системно-деятельностный подход, позволяющий содержательно уточнить объект и обобщить онтологический и гносеологический планы, историческое и логическое восхождение от конкретного к абстрактному и от абстрактного к конкретному, использовать метод распредмечивания основного продукта, сравнительно-исторический анализ и контентанализ документов. Информационная природа продукта объективирует возможности информационного подхода, а специфика объекта теоретической мысли - приводит к использованию интуитивной логики» $[1$, с. $18-19]$. Так сама Э.К. Беспалова описывает примененные ею методы интеллектуального анализа.

Какие методологические основания применяет ученый, разрабатывая собственную теорию истории библиографической мысли на фундаменте российской библиографии и библиографоведения?

Истоки теоретической мысли лежат сразу в нескольких плоскостях развития библиографической практики. Динамическое развитие информационных процессов влекло за собой объединение участков библиографической деятельности, приводило к формированию отдельных направлений библиографической практики - общему и специальному библиографированию, вторичному библиографированию, библиографической журналистике, библиотечной и книготорговой библиографии. Каждая из этих граней библиографической деятельности обогащает теоретическое представление о сущности данного вида информационной деятельности, выстраивая ее более точную концептуальную конструкцию. Закономерностью первого этапа истории теоретической мысли в библиографоведении является книговедческая концепция, где главным информационным феноменом доциф- 
ровой эпохи человечества выступает книга. Базовое отношение «книга - читатель» в ранних проявлениях пока выдвигает на первый план только книгу как единый исходный объект деятельности и теоретического отражения, читатель пока не явен и не очевиден, но он опосредован через книгу. Библиографическая мысль в своем эволюционном развитии пройдет три этапа, выясняя сущность библиографии: сущностью первого порядка стала книга, второго порядка - библиографическое пособие, третьего порядка - библиографическая деятельность.

Анализу книги как категориально-генетического понятия в отношении с аффинной (зависимой) и диагенетической (независимой) библиографической информации Э.К. Беспалова посвящает вторую главу «Исторические истоки библиографии. Библиография и книжное дело» $[1$, с. $38-$ 51]. Ученый доказывает, что именно тиражирование документа сделало его

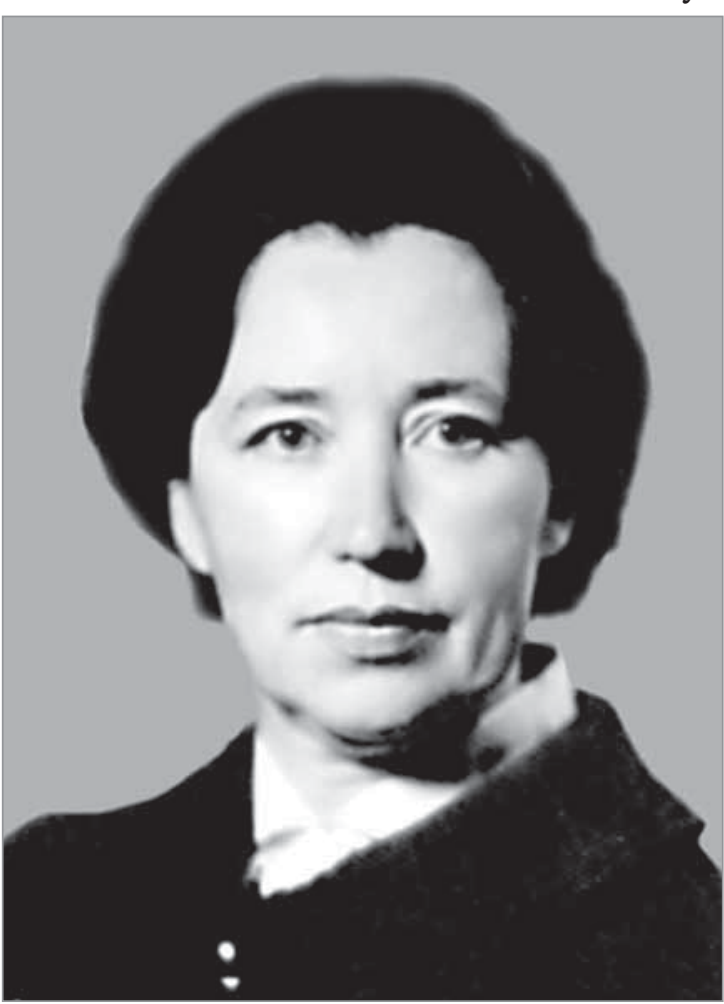

Э.К. Беспалова даментальную связь между системами. А книга и библиографический документ, подвергаясь процессам переработки и обработки, дают библиометрические характеристики системе «знания».

Главным методологическим принципом в своих концептуальных воззрениях Эмилия Константиновна считала методологию деятельностного подхода, воспринятую ею из работ по диалектическому материализму. «Введение активной и при том сознательной деятельности человека в структуру познания и замена двухчленной формулы (знание - объект) трехчленной (знание деятельность - объект) является важнейшим достижением исторического материализма», приводит она слова А.И. Ракитова $[1$, c. 21].

Применяя данный подход к историческому исследованию, Э.К. Беспалова выделяет два слоя деятельности - деятельность субъекта познакнигой, и это новое ее качество, порожденное количественной стороной, создало необходимость вторичной структуры документа (данные титульного листа), обеспечивающей необходимую коммуникацию. «Без относительно развитой вторичной структуры книга не существует в своем качестве общественно-значимого документа. Она, условно говоря, “предкнига” $[1$, c. 44].

Объясняя базовые подходы своего историко-теоретического взгляда на библиографию, Э.К. Беспалова также останавливается на обязательности обращения к информационному подходу, который основывается на взаимодействии и последовательности систем «знание», «документ» и «библиографический документ», выраженных во взаимосвязи формы и содержания, документальных форм книги и библиографического пособия с содержательным наполнением знания. Книга является системообразующим центром всех трех систем, синтезируя в себе три вида деятельности. Знание, являясь содержательным истоком, обеспечивает фундостаточно сложным обстоятельством в условиях экспликации исторического знания. В истории библиографоведения это усугубляется добавлением третьего слоя, в результате получаем: деятельность практика-библиографа, в работе которого в разной степени осознанности присутствует научная рефлексия, деятельность теоретика библиографии в качестве исторического персонажа, деятельность историка библиографоведения. Таким образом, особенность библиографической деятельности дает основание для расширения теоретического поля интерпретации за счет добавления библиографического пособия как исторического источника теоретической мысли. С точки зрения теоретического распредмечивания библиографический документ играет фундаментальную роль в оценке процессов библиографирования, замысла, методических установок и общественных потребностей в конкретный исторический период. С помощью новых слоев деятельности на опосредованном уровне через библиогра- ния и деятельность историка, что является 
фическое пособие можно вывести сущностные характеристики других действующих лиц представителей книжной индустрии, читателей.

Э.К. Беспалова поднимает традиционные теоретические постулаты, ставшие уже в какой-то степени классическими, общепринятой теории библиографии, переосмысливает их с позиций историко-теоретического ракурса рассмотрения библиографических явлений. Так она подходит к одному из ключевых вопросов общего библиографоведения - дифференциации библиографии и библиографических пособий. Анализируя современные позиции, восходящие к Ю.С. Зубову [2] и Ю.А. Чяпите [3], Беспалова отходит от содержательно-предметного деления на универсальную (в национальных или языковых границах), комплексную и отраслевую библиографию как главного в историческом развитии, базирующегося на формуле «энциклопедичность - дифференциация - интеграция». Она замечает, что здесь прямая связь науки и библиографического ее отражения чрезмерно экстраполирована, поскольку пропущено важное звено - первичный документ. Библиография связана с наукой опосредованно, через первичный документ, в первоначальной цепочке «наука - вторичный документ» (Ю.С. Зубов) отсутствует среднее звено - «книга». Скорее всего, первичный и вторичный документальные потоки отождествлялись по отношению к системе «наука».

Библиографовед приводит ряд доводов, корректирующих общепринятую позицию:

- система «книга» не может быть содержательно адекватна системе «наука», книжное отражение научного знания дает лишь общее «панорамное» представление о накопленных знаниях;

- процесс «дифференциация - интеграция» в документном мире выглядит иначе, для него свойственна междокументная интеграция, реализуемая через библиографическую обработку;

- библиографический уровень отражения научного знания еще более отстает от самого его содержания по причине того, что учет документов не всеобъемлющий, зато усиливалась ретроспективная тенденция, именно такими были первые универсальные ретроспективные своды.

Капитализация общественного производства привела процессы библиографирования к обозначению национальных границ государств и наметившейся тенденции текущего учета. Для первичного документального потока на новой производственной платформе существенными характеристиками стали время и место издания печатной книги. Эти признаки легли в основу структуры библиографических документов, дифференцировав мировую библиографическую практику.

Связь между двумя документными системами, первичной и вторичной, благодаря этим общим формальным признакам более близка и существенна, чем с системой научного знания. Поэтому, по мнению библиографоведа, признаки времени и места издания выступают исторически исходными принципами дифференциации библиографии. Эти признаки ограничили мировую документную систему по критериям времени и географического пространства, что привело к исходной дифференциации библиографической продукции на таймерные (ограниченные по времени) и хорографические (ограниченные по месту) подсистемы библиографического отражения. Таймерные подсистемы эволюционировали и развивались в сторону от ретроспективного анализа документа до необходимости текущей фиксации первичных потоков и далее, включая прогностические цели. Хорографические - производны и актуализируются в связи с национально-государственными процессами, ограничивая документальные потоки по территориальному, государственному (языковому) признаку.

На основе сочетания двух признаков первоначально возникают таймерно-хорографические библиографические системы в виде текущей или ретроспективной, государственной или национальной библиографии. Такие системы стали первой главной тенденцией деления библиографии, предшествующей дифференциации на основе содержания документов. Беспалова считает фундаментальным именно данный видовой ряд, другие разновидности появляются как производные, выделяемые по основаниям последующих порядков. Таким образом, историко-теоретическое видение информационных процессов предлагает новые позиции в теоретическом дискурсе современного библиографоведения.

Остановимся еще на одном аспекте, поднимаемом библиографоведом, в рамках обоснования исторической эпистемологии библиографоведения. Что является фактом и источником истории библиографоведения? Теория исторического процесса дает возможность сопоставить такие понятия, как «исторический 
факт», «факт истории теоретической мысли», выделить «факт-событие», «факт-источник», «факт-знание». Историю библиографоведения прежде всего интересует документ как «факт-источник» теоретической мысли, представленный тремя типами: библиографической продукцией, методико-библиографическими и библиографоведческими документами.

Специфика библиографоведения диктует собственные источники получения теоретического знания - это теоретические работы и библиографические пособия. Тем самым последние обретают функцию и исторического памятника, и источника истории теоретической мысли. Беспалова выделяет два уровня теоретической работы с библиографическим пособием: описательный и абстрагированный (теоретические установки, методика и технология составления). Здесь наибольшую историкотеоретическую ценность имеют универсальные указатели книги и указатели библиографических пособий.

Природа библиографии, ее деятельностная эволюция наполнена неочевидным на первый взгляд, но достаточно насыщенным теоретическим полем, позволяющим анализировать информационные процессы и явления во многих плоскостях - социальной, культурной, политической, научной и т. п. Библиографические источники во временном-пространственном отношении преодолевают свою «вспомогательность», сами олицетворяют вполне самостоятельный метод познания. Но и для собственной теоретической рефлексии библиографоведение избирает следующие группы исторических источников, предложенные в исследовании Л.А. Егорновой [4]:

- труды по истории общества, культуры, науки, книжного дела и т. д., отражающие внешнюю обусловленность библиографии;

- библиографические и библиографоведческие работы, раскрывающие внутреннюю логику развития библиографических процессов;

- научное и практическое наследие библиографа, «литература о нем», раскрывающая «логику деятельности субъекта библиографии»;

- группа источников, показывающих влияние библиографической информации на социальную практику (науковедческие статистические материалы, официальная документация изучения читателей).

Корректируя данную дифференциацию, Э.К. Беспалова предлагает свести источники истории и теории библиографоведения до двух групп, объединяя первую и четвертую группы: труды, характеризующие социальный контекст; а также вторую и третью группы: библиографическая и библиографоведческая продукция, включающая два типа документов. Особое место в истории теоретической мысли занимает библиографическая продукция как результат деятельности, несущий теоретическое знание двух уровней - описательного (в случае осмысления общего движения библиографической практики) и абстрагированного (в случае выявления в библиографическом пособии теоретической составляющей в технологических и концептуальных аспектах).

Настоящая статья представляет собой только частичный разбор первой главы «Общие вопросы исторической эпистемологии библиографоведения» книги Э.К. Беспаловой [1], состоящей из 13 глав. В многочисленных проявлениях историко-библиографических фактов, наблюдаемых в истории с эпохи Древней Руси, библиографовед видит основания для зарождения теоретической мысли по всем направлениям библиографической деятельности: истоки книговедческой и читателеведческой концепций, становление библиографической методики в контексте теоретической проблематики и т. д.

Беспалову не так просто читать и понимать, реальная библиографическая практика многими представителями библиотечного и библиографического дела воспринимается больше технологически и порой не расположена к философским обобщениям и конструкциям. Предложенный дискурс небольшого фрагмента научного наследия, оставленного видным представителем библиографоведения, есть стремление актуализировать и интерпретировать идеи ученого, а также расставить должные акценты с позиций выдающегося вклада Эмилии Константиновны в разработку теории истории библиографии, исторического метода библиографоведения. Библиографоведение, теоретический и методологический фундамент библиографической практики - сложноорганизованное, эволюционное явление, пустившее глубокие корни научного знания. На современном этапе библиографоведение отличает множественность возможностей развития в зависимости от концептуального подхода к объекту познания. Все это, в конечном счете, способствует формированию целостности науки.

Как же обозначить научный метод Э.К. Беспаловой? Думается, его можно назвать 
историческим методом библиографоведения. Библиографическая деятельность и библиографическая наука, взятые в историческом контексте, дают видение отрасли как самостоятельного феномена, встроенного в общие социальные и научные процессы. Поэтому одна из перспективных возможностей - развитие библиографоведения, под которым мы понимаем весь комплекс научных проблем фактографического, теоретического, методологического характера, так или иначе связанных с историей библиографии и библиографоведения, с формированием теоретического мировоззрения крупнейших библиографов.

Научные труды Эмилии Константиновны отражают реализацию этого метода [5; 6]. Архив ученого передан в Библиотеку Российской академии наук [7]. Объектами исторического подхода становились буквально все явления библиографической природы [8; 9], будь то отдельные направления библиографической деятельности, например рекомендательная библиография, вторичное библиографирование, создание репертуаров русской книги $[10 ; 11]$; фундаментальные и типические библиографические труды и знаковые события, происходившие на протяжении тысячелетней истории отечественной библиографии (деятельность «Русского библиографического общества», библиотечные и библиографические съезды) [12; 13]; профессиональное мировоззрение выдающихся библиографов - Б.С. Боднарского, А.М. Ловягина, В.И. Межова, К.Н. Дерунова, Н.В. Здобнова и многих других деятелей русской и мировой библиографии [14]; теоретико-методологические выводы и обобщения исторического пути русской библиографии $[15 ; 16]$.

Продолжателями методологической линии исторических исследований Э.К. Беспаловой стали ее аспиранты и докторанты. Историю и современные проблемы библиографической подготовки библиотечных кадров отразили Л.П. Машенцева [17] и 3.Д. Дамбинова [18], удостоенные степени кандидата педагогических наук по специальности «Библиотековедение, библиографоведение и книговедение». Истории библиографии и библиографоведения, теоретико-методологическим проблемам библиографии в трудах русских библиографов посвятили свои кандидатские работы Н.И. Васькова [19], И.Г. Хомякова [20], Е.Ю. Ажеева [21]. Под руководством Э.К. Беспаловой восемь аспирантов защитили канди- датские диссертации, некоторые из них продолжают работать над докторскими диссертациями.

Влияние метода российского библиографоведа имело международное значение, Эмилия Константиновна плодотворно сотрудничала с представителями библиографической науки и образования Болгарии и Китая. В 1992 и 1995 гг. по приглашению Института библиотековедения и информатики Уханьского университета, Национальной библиотеки Китая (Пекин) она читала лекции по проблемам теории, истории и методологии библиографии для аспирантов, докторантов и библиотечных специалистов [22].

Своеобразие метода Беспаловой, на наш взгляд, заключается в проницательном «рентгеновском» сканировании библиографической реальности различных исторических периодов с позиций выявления теоретических истоков и закономерных процессов на уровне современных философских воззрений, обусловивших сложившуюся зрелость библиографической науки и практики. Поэтому Э.К. Беспалова привнесла в историю русской библиографии и библиографоведения новый познавательный пласт, придающий объемность, целостность библиографоведческого знания и отражающий уникальность феномена библиографии. Чем шире изучается наследие Эмилии Константиновны, тем явственнее раскрывается метод Беспаловой.

\section{Список источников}

1. Беспалова Э.К. Формирование библиографической мысли в России (до 60-х гг. XIX в.). СанктПетербург : Профессия, 2007. 320 с.

2. Зубов Ю.С. Библиография как система свернутого знания // Теоретико-методологические проблемы современного советского библиографоведения. Москва, 1981. С. 23-40.

3. Чяпите Ю.А. Проблемы классифицирования библиографических пособий и библиографии : дис. ... канд. пед. наук. Ленинград, 1978. 236 с.

4. Егорнова Л.А. Формирование в СССР истории библиографии как научной дисциплины, 19171981 гг. : дис. ... канд. пед. наук. Москва, 1982. $311 \mathrm{c}$.

5. Эмилия Константиновна Беспалова : биобиблиографический указатель : к 75-летию со дня рождения. Москва, 2005. 75 с.

6. Бокан М.Г., Баженова Н.М. Научное и архивное наследие Э.К. Беспаловой в фондах Библиотеки РАН // Библиография. 2014. № 3. С. 129-133. 
7. Бокан М.Г. Работа с архивом Э.К. Беспаловой в фонде библиотековедения БАН // Петербургская библиотечная школа. 2018. № 1 (61). С. $154-156$.

8. Беспалова Э.К. Избранное: статьи за 20 лет. В 2 т. Москва : МГУК, 1994. Т. 1. Методология и теория библиографии. 276 с.

9. Беспалова Э.К. Избранное: статьи за 20 лет. В 2 т. Москва : МГУК, 1994. Т. 2. История библиографии. 322 с.

10. Беспалова Э.К. Теория рекомендательной библиографии: состояние и проблемы : автореф. дис. ... канд. пед. наук. Москва, 1975. 24 с.

11. Беспалова Э. К. Практика вторичного библиографирования как исток теории библиографии // Современные проблемы библиографии и библиографоведения : межвуз. сб. науч. тр. Москва, 1986. С. $67-85$.

12. Беспалова Э.К. Как закрывали Русское библиографическое общество // Советская библиография. 1989. № 1. С. 75-81.

13. Беспалова Э.К. Как закрывали Русское библиографическое общество // Советская библиография. 1989. № 2. С. 47-54.

14. Беспалова Э.К. Биографический жанр в библиографии. Персоналия библиографов. Москва : МГУКИ, 2003. 212 с.

15. Беспалова Э.К. Теоретическое введение в историю библиографии // Библиография. 2003. № 5. C. $41-62$.
16. Беспалова Э.К. История российской библиографии. Начальный период. Библиография в России с IX-XI вв. до 60-х гг. XIX в. // Библиография. 2006. № 3. С. 79-99.

17. Машенцева Л.П. Возникновение и развитие библиографической подготовки библиотечных кадров высшей квалификации в СССР : автореф. дис. ... канд. пед. наук. Москва, 1986. 16 с.

18. Дамбинова 3.Д. Становление и перспективы развития библиографической деятельности как предмета преподавания : автореф. дис. ... канд. пед. наук. Москва, 1987. 16 с.

19. Васькова Н.И. Библиографическая деятельность Б.С. Боднарского : автореф. дис. ... канд. пед. наук. Москва, 1989.16 с.

20. Хомякова И.Г. Теоретико-методологические проблемы библиографии в трудах Н.А. Рубакина. Москва : Изд-во МГУК, 1996. 220 с.

21. Ажеева Е.Ю. Н.В. Здобнов как историк русской библиографии : (теоретико-методологические аспекты). Москва : МГИК, 1994. 295 с.

22. Каратыгина Т.Ф. Прочно занявшая свое место в первой десятке наиболее значимых библиографоведов России (к 75-летию известного отечественного библиографоведа Э.К. Беспаловой) // Библиотечное дело - 2005: деятельность библиотек и развитие информационной культуры общества : материалы 10-й Междунар. науч. конф. (Москва, 20-22 апр. 2005 г.). Москва, 2005. С. $310-311$.

\section{Historical Method in Bibliography Science by E.K. Bespalova}

\section{Elena Y. Azheeva,}

Arctic State Institute of Art and Culture, 4 Ordzhonikidze Str., Yakutsk, 677000, The Sakha Republic (Yakutia), Russia

ORCID 0000-0002-5701-4230; SPIN 6779-7370

E-mail: azheyeva@mail.ru

Abstract. The scientific legacy of Emilia Konstantinovna Bespalova, well-known Russian bibliographer, theorist and historian of bibliography, includes more than 200 works. She laid her own line in theoretical and methodological understanding of bibliography science and activity. "Formation of Bibliographic Thought in Russia (Up to the 60s of the 19th century)" is the last fundamental work of E.K. Bespalova; it describes the philosophical and methodological explication of bibliography as a naturally occurring phenomenon of information nature. There was formed unique method of analysis that considered historical and biblio- 
graphic facts in the context of professionalization of bibliographic activity. The analysis of bibliographic phenomena applied by E.K. Bespalova can be generally described as combination of modern theoretical knowledge on bibliography, methodology of system-activity approach and philosophy of historical process. The historical-theoretical method of studying bibliographic activity at different stages of its development allows a modern researcher to see the institutional significance of bibliographic processes as one of the full-fledged components of the global information picture.

Analyzing the initial, original object of bibliographic activity - a book, the scientist proves that it was the process of replication and therefore the need to create the secondary structure of a book in a form of title page, which made a book to be the "book". Through the concept of "book" E.K. Bespalova also traces interaction and sequential connection of three systems - "knowledge", "book" ("document") and "bibliographic document". From the point of view of cognitive potential of the history of bibliography, bibliographical guide is of historical and theoretical interest being the result of activity and the object of desobjectivation in it of the conceptual theoretical-methodological and historical representations of authors, composers and doers of the history of bibliography. As the main differentiation of bibliographic products, Bespalova puts forward the division into timer bibliographic subsystems (reflection of current, retrospective, prospective primary flow) and chorographic subsystems that restrict documentary flows by the territorial and linguistic principle. The historical method by E.K. Bespalova reveals a wide range of theoretical foundations that enrich modern bibliography science.

Key words: E.K. Bespalova, history of bibliography, theory of bibliography and bibliography science, technology and methods of bibliography, methodology of the history of bibliography, historical bibliography science, history of bibliographic thought, theory of historical process, bibliography science.

Citation: Azheeva E.Y. Historical Method in Bibliography Science by E.K. Bespalova, Bibliotekovedenie [Russian Journal of Library Science], 2020, vol. 69, no. 4, pp. 399-407. DOI: 10.25281/0869-608X-202069-4-399-407.

\section{References}

1. Bespalova E.K. Formirovanie bibliograficheskoi mysli $v$ Rossii (do 60-kh gg. XIX v.) [Bibliographic Thought Formation in Russia (Up to the 1860s)]. St. Petersburg, Professiya Publ., 2007, 320 p.

2. Zubov Yu.S. Bibliography as a System of Surrogate Knowledge, Teoretiko-metodologicheskie problemy sovremennogo sovetskogo bibliografovedeniya [Theoretical and Methodological Issues of Modern Soviet Bibliography Studies]. Moscow, 1981, pp. 23-40 (in Russ.).

3. Chyapite Yu.A. Problemy klassifitsirovaniya bibliograficheskikh posobii i bibliografii [Classification Issues of Bibliographic Manuals and Bibliography], cand. ped. sci. diss. Leningrad, 1978, 236 p.

4. Egornova L.A. Formirovanie v SSSR istorii bibliografii kak nauchnoi distsipliny, 1917-1981 gg. [Formation of the History of Bibliography as a Scientific Discipline in the USSR, 1917-1981], cand. ped. sci. diss. Moscow, 1982, 311 p.

5. Emiliya Konstantinovna Bespalova: biobibliograficheskii ukazatel': $k$ 75-letiyu so dnya rozhdeniya [Emilia Konstantinovna Bespalova: biobibliographic index: to the 75th anniversary of her birth]. Moscow, 2005, 75 p.

6. Bokan M.G., Bazhenova N.M. E.K. Bespalova's Scientific and Archival Heritage Stored in the
Library of the Russian Academy of Sciences, Bibliografiya [Bibliography], 2014, no. 3, pp. 129-133 (in Russ.).

7. Bokan M.G. Working with the Archive of E.K. Bespalova in the Library Science Collection of the Academy of Sciences Library, Peterburgskaya bibliotechnaya shkola [Petersburg Library School], 2018, no. 1 (61), pp. 154-156 (in Russ.).

8. Bespalova E.K. Izbrannoe: stat'i za 20 let. V 2 t. [Selected Works: Articles for 20 Years. In 2 volumes]. Moscow, MGUK Publ., 1994, vol. 1, 276 p.

9. Bespalova E.K. Izbrannoe: stat'i za 20 let. V 2 t. [Selected Works: Articles for 20 Years. In 2 volumes]. Moscow, MGUK Publ., 1994, vol. 2, 322 p.

10. Bespalova E.K. Teoriya rekomendatel'noi bibliografii: sostoyanie i problemy [Theory of Recommendation Bibliography: Status and Issues], cand. ped. sci. diss. abstr. Moscow, 1975, 24 p.

11. Bespalova E.K. The Practice of Secondary Bibliographing as the Source of the Theory of Bibliography, Sovremennye problemy bibliografii i bibliografovedeniya: mezhvuz. sb. nauch. tr. [Modern Issues of Bibliography and Bibliography Studies: interuniversity collection of scientific papers]. Moscow, 1986, pp. 67-85 (in Russ.). 
12. Bespalova E.K. How the Russian Bibliographic Society Was Being Shut Down, Sovetskaya bibliografiya [Soviet Bibliography], 1989, no. 1, pp. 75-81 (in Russ.).

13. Bespalova E.K. How the Russian Bibliographic Society Was Being Shut Down, Sovetskaya bibliografiya [Soviet Bibliography], 1989, no. 2, pp. 47-54 (in Russ.).

14. Bespalova E.K. Biograficheskii zhanr v bibliografii. Personaliya bibliografov [Biographical Genre in Bibliography. Bibliographers' Personalities]. Moscow, MGUKI Publ., 2003, 212 p.

15. Bespalova E.K. Theoretical Introduction to the History of Bibliography, Bibliografiya [Bibliography], 2003, no. 5, pp. 41-62 (in Russ.).

16. Bespalova E.K. The History of Russian Bibliography. Initial Period. Bibliography in Russia from the 9th11th Centuries to the 1860s, Bibliografiya [Bibliography], 2006, no. 3, pp. 79-99 (in Russ.).

17. Mashentseva L.P. Vozniknovenie i razvitie bibliograficheskoi podgotovki bibliotechnykh kadrov vysshei kvalifikatsii v SSSR [Emergence and Development of the Bibliographic Training of Highly Qualified Library Personnel in the USSR], cand. ped. sci. diss. abstr. Moscow, 1986, 16 p.

18. Dambinova Z.D. Stanovlenie i perspektivy razvitiya bibliograficheskoi deyatel'nosti kak predmeta prepodavaniya [Formation and Development Prospects of the Bibliographic Activity as a Teaching Subject], cand. ped. sci. diss. abstr. Moscow, 1987, 16 p.

19. Vaskova N.I. Bibliograficheskaya deyatel'nost' B.S. Bodnarskogo [B.S. Bodnarsky's Bibliographic Activity], cand. ped. sci. diss. abstr. Moscow, 1989, 16 p.

20. Khomyakova I.G. Teoretiko-metodologicheskie problemy bibliografii v trudakh N.A. Rubakina [Theoretical and Methodological Issues of Bibliography in N.A. Rubakin's Works]. Moscow, MGUK Publ., 1996, $220 \mathrm{p}$.

21. Azheeva E.Yu. N.V. Zdobnov kak istorik russkoi bibliografii: (teoretiko-metodologicheskie aspekty) [N.V. Zdobnov as a Historian of Russian Bibliography: (Theoretical and Methodological Aspects)]. Moscow, MGIK Publ., 1994, 295 p.

22. Karatygina T.F. She Firmly Took her Place among the Top Ten Most Significant Bibliographers of Russia (To the 75th Anniversary of the Famous Russian Bibliographer E.K. Bespalova), Bibliotechnoe delo - 2005: deyatel'nost' bibliotek i razvitie informatsionnoi kul'tury obshchestva: Materialy 10-i Mezhdunar. nauch. konf. (Moskva, 20-22 apr. 2005 g.) [Proc. 10th Int. Sci. Conf. "Librarianship - 2005: Library Activities and Society's Information Culture Development” (Moscow, April 20-22, 2005)]. Moscow, 2005, pp. 310-311 (in Russ.). 